\title{
Host-associated allozyme variation in tree cambium miners, Phytobia spp. (Diptera: Agromyzidae)
}

\author{
T Nyman $^{1,3}$, T Ylioja ${ }^{2,4}$ and H Roininen ${ }^{1,2}$ \\ ${ }^{1}$ Department of Biology, University of Joensuu, P.O. Box 111, FIN-80101 Joensuu, Finland; ${ }^{2}$ Punkaharju Research Station, Finnish \\ Forest Research Institute, FIN-58450 Punkaharju, Finland
}

The larvae of the agromyzid flies that belong to the genus Phytobia Lioy feed by mining in the differentiating xylem just below the cambium of growing forest trees. The genus, which is apparently one of the most primitive groups in the Agromyzidae, comprises over 50 currently recognized species. Most of the species are mono- or oligophagous, and the host plants belong to numerous genera in about 60 families. Thus, Phytobia is an attractive candidate for studies on the evolution of insect-plant relationships. In spite of this, the taxonomy of Phytobia is currently poorly understood, mainly because the morphological differences between species are small. We used allozyme electrophoresis to investigate whether molecular markers could be used to separate and identify species in Phytobia, and to study the patterns of host use in the group. For this, we collected Phytobia larvae from eight host tree species occurring in southern Finland. An analysis of 10 variable allozyme loci showed that there are probably five species of Phytobia that feed on the hosts included in our study: one occurs on birches (Betula pubescens Ehrh. and $B$. pendula Roth) and alders (Alnus incana (L.) Moench and $A$. glutinosa (L.) Gaertn.), one on rowan (Sorbus aucuparia L.), and three species with overlapping feeding ranges on aspen (Populus tremula L.) and two willow species (Salix phylicifolia L. and S. caprea L.). Because birches and alders belong to the plant family Betulaceae, rowan to Rosaceae, and aspen and willows to Salicaceae, the host associations of the individual fly species can be explained by the taxonomic affinities of the hosts. However, our results also show that on a larger scale the evolution of host-plant associations in Phytobia cannot be explained by strict parallel cladogenesis (cospeciation) between the flies and their hosts.

Heredity (2002) 89, 394-400. doi:10.1038/sj.hdy.6800158

Keywords: Agromyzidae; allozymes; coevolution; host specificity; insect-plant interactions; parallel cladogenesis; Phytobia; speciation

\section{Introduction}

Most plant-feeding insects feed on only one or a few host species (Jermy, 1984; Bernays and Graham, 1988), but the exact proportion of true specialists is difficult to determine. In fact, it is very likely that the number of monophagous insect species is currently underestimated, because speciation and ecological specialization in insects is frequently accompanied by little or no change in morphology (Mayr, 1963; Diehl and Bush, 1984; Drès and Mallet, 2002). Thus, an adaptive radiation to multiple hosts may result in a complex of morphologically indistinguishable host races or sibling species, which are then erroneously interpreted as one polyphagous species (Diehl and Bush, 1984; Drès and Mallet, 2002). However, cryptic species or host races can sometimes be distinguished by using molecular methods, such as allozyme electrophoresis (Feder et al, 1988; McPheron et al,

T Nyman, Department of Biology, University of Joensuu, PO Box 111, FIN-80101 Joensuu, Finland. E-mail: Tommi.Nyman@joensuu.fi ${ }^{3}$ Current address: Department of Organismic and Evolutionary Biology, Harvard University, 26 Oxford Street, Cambridge, MA 02138, USA. ${ }^{4}$ Current address: Department of Biological Sciences, Dartmouth College, Hanover, NH 03755, USA.

Received 28 January 2002; accepted 30 June 2002
1988; Roininen et al, 1993; Emelianov et al, 1995; Condon and Steck, 1997; Nyman, 2002; Aguin-Pombo, 2002), random amplified polymorphic DNA (De Barro et al, 1995; Pornkulwat et al, 1998), or DNA sequencing (Scheffer, 2000; Scheffer and Wiegmann, 2000).

The aim of this study was to use allozyme electrophoretic data to clarify species identification in the agromyzid genus Phytobia Lioy. The genus consists of species that are separated from the rest of the Agromyzidae not only morphologically but, more importantly, based on the unique feeding habit of their larvae (von Tschirnhaus, 1971; Spencer, 1976; Spencer and Steyskal, 1986): the growing larvae mine within the cambial cylinder of growing trees and bushes, tunnelling several meters downwards from tree crowns towards the base (Barnes, 1933; Kangas, 1935; Hanson and Benjamin, 1967; Ylioja et al, 1998). Host trees fill the larval tunnels with parenchyma tissue that keep the tunnels visible within the annual rings of trees (Greene, 1914; Kangas, 1935; Gregory and Wallner, 1979; Ylioja et al, 1998). In trees with high commercial value used for furnishing and other specialty purposes, the dark larval tunnels are often considered defects, and can decrease the value of raw material considerably (Kangas, 1935; Hanson and Benjamin, 1967; Spencer, 1976; Spencer and Steyskal, 1986; Ylioja et al, 1998). 
In addition to being a pest for the forestry industry, Phytobia is a promising group for evolutionary studies. It is apparently one of the most primitive genera in the Agromyzidae (Nowakowski, 1962; Spencer, 1990), and larval tunnels have been found in fossil wood dating back to the Eocene, ca. 37-58 million years ago (Süss and Müller-Stoll, 1980; but see Spencer and Steyskal, 1986, for a cautionary note). The globally distributed genus comprises over 50 currently recognized species, all of which are apparently mono- or oligophagous (Spencer and Steyskal, 1986); the host plant species belong to numerous genera in about 60 families (Süss and Müller-Stoll, 1980; Spencer, 1990). Thus, Phytobia can be used to study how the utilization of different host species has changed during the evolutionary history of insects.

Studying the evolution of host-plant associations in Phytobia would require knowledge on the phylogenetic relationships between the species within the genus, but even the basic taxonomy of the group is unclear. Species descriptions in Phytobia are based on morphological characters of adults, which can be very similar between some species (Spencer, 1976; Spencer and Steyskal, 1986). In many cases, only small differences in male genitalia may be used to differentiate the species (Spencer, 1976; Spencer and Steyskal, 1986). The adults are difficult to catch and rear, and the white, slender larvae, which can be easily collected from young trees, offer few useful morphological characters for taxonomic studies (Barnes, 1933; Kangas, 1935; Spencer, 1976; Süss and Müller-Stoll, 1980). Consequently, it is not surprising that the taxonomy of the genus has been changing constantly, and the host ranges of many species are unknown (Spencer, 1976, 1990; Spencer and Steyskal, 1986).

The taxonomy of Phytobia has been most extensively studied in Europe and North America, but even in these areas there is considerable confusion about the number of known species. During the first half of the last century, Kangas $(1935,1949)$ collected and described cambium miners in southern Finland. The first two new species that he described were $P$. betulae Kangas on Betula spp., and P. aucupariae Kangas on Sorbus aucuparia L. Kangas (1949) considered that European Salicaceae hosts support three Phytobia species: P. cambii Hendel and P. barnesi Hendel on Populus and Salix species, and P. tremulae Kangas on Populus tremula L. However, these three Salicaceae-feeding species have later been synonymized under P. cambii (Spencer, 1976, 1990; Martinez et al, 1985). Recently, even $P$. betulae has been synonymized with $P$. cambii (von Tschirnhaus, 2000).

The purpose of our study was to investigate whether allozyme electrophoretic markers can be used to differentiate between Phytobia species occurring on eight host tree species belonging to five different genera in three plant families. An allozyme-based identification method would circumvent the need to rear the larvae to adults, facilitate rapid identification, and provide tools for research aiming at management of Phytobia.

Furthermore, we wanted to study whether the host ranges of the species can be explained by the phylogenetic relationships of the host plants, because it has been suggested that endophagous (mining) larval habits may enhance the probability of parallel cladogenesis $(=$ cospeciation) between insects and their hosts (Farrell and Mitter, 1990, 1998).

\section{Materials and methods}

\section{Life history of Phytobia}

All Phytobia species that have been studied are univoltine (Kangas, 1935, 1949; Spencer, 1976). In the spring, the ca. $0.5 \mathrm{~cm}$ long, black females oviposit into growing shoots of their host trees (Barnes, 1933; Kangas, 1949; Ylioja et al, 1998; Ylioja, 2000). The larva starts mining down the shoot, and when it reaches the trunk, it continues downward, mining in the differentiating xylem just below the cambium (Gregory and Wallner, 1979; Ylioja et al, 1998). The feeding tunnel can be seen as a brownish 1-2 mm wide streak under the bark of the host tree (Spencer, 1976; Ylioja et al, 1998). The larvae may reverse their direction and mine up and down if they reach the base of the tree (Greene, 1914; Grossenbacher, 1915; Kangas, 1935; Hanson and Benjamin, 1967; Ylioja et al, 1998). In autumn, the ca. $2 \mathrm{~cm}$ long larvae of most Phytobia species exit the tree via a vertical slit that they cut in the bark; pupation and overwintering occurs in the ground, and the adults emerge the next spring (Barnes, 1933; Kangas, 1935, 1949; Hanson and Benjamin, 1967; Spencer, 1976). However, in some species (eg, P. aucupariae), the larvae overwinter under the bark and resume feeding the next spring (Grossenbacher, 1915; Kangas, 1949, 1955; Spencer, 1976; Spencer and Steyskal, 1986). In these species, the larvae exit the tree and pupate on the ground in late spring, and the adults emerge, mate, and oviposit later in the summer (Grossenbacher, 1915; Kangas, 1949, 1955; Spencer, 1976).

\section{Sample collection and electrophoresis}

Following Kangas (1935, 1949), we collected larvae of Phytobia from the surroundings of the Punkaharju Research Station in southeastern Finland $\left(61^{\circ} 48^{\prime} \mathrm{N}\right.$, $\left.29^{\circ} 20^{\prime} \mathrm{E}\right)$. Larvae were collected by peeling the bark off young 2-5 $\mathrm{m}$ tall trees representing eight host species: Betula pendula Roth (40 larvae from 12 trees), B. pubescens Ehrh. (60 larvae from 19 trees), Alnus incana (L.) Moench (25 larvae from 21 trees), A. glutinosa (L.) Gaertn. (20 larvae from 10 trees), Populus tremula L. (15 larvae from 11 trees), Salix phylicifolia L. (35 larvae from 25 trees), S. caprea L. (30 larvae from 19 trees), and Sorbus aucuparia L. (30 larvae from 23 trees). Of these, Betula and Alnus belong to the plant family Betulaceae, Populus and Salix to Salicaceae, and Sorbus to Rosaceae. Most collections were made between 28 July and 20 August in 1997; the larvae infesting Sorbus aucuparia were, however, collected from the same location in July 1998, because the larvae collected in the previous autumn were too small for electrophoresis. All larvae were stored in Eppendorf tubes at $-80^{\circ} \mathrm{C}$.

In all, 255 larvae were used for electrophoresis (Table 1). The samples were homogenized in $60 \mu \mathrm{l}$ sample buffer (Ferguson, 1980), after which the tubes were centrifuged at $10000 \mathrm{rpm}$ for $4 \mathrm{~min}$; $45 \mu \mathrm{l}$ of the supernatant was used in standard starch gel electrophoresis according to the protocol outlined in Vuorinen (1984). The horizontal $12 \%$ starch gels were cut into $2 \mathrm{~mm}$ thick slices and stained for specific enzymes. Buffer systems were as in Roininen et al (1993) and Nyman et al (1998), except that Fumh-1 and Fumh-2 were scored from buffer B gels (see Nyman et al, 1998).

Ten variable enzyme loci were scored: phosphoglucomutase (Pgm, EC 5.4.2.2.), malic enzyme (Me, EC 1.1.1.40), 
Table 1 Allele frequencies and sample sizes $(N)$ at ten polymorphic loci in Phytobia larvae collected from eight different host species

\begin{tabular}{|c|c|c|c|c|c|c|c|c|c|c|c|c|}
\hline \multirow[t]{2}{*}{ Locus } & \multirow[t]{2}{*}{ Allele } & \multicolumn{11}{|c|}{ Host } \\
\hline & & B. pen & B. pub & A. inc & A. glu & P. tre & S. phy & S. cap & S. $a u c$ & 'Sal 1' & 'Sal 2' & 'Sal 3' \\
\hline \multirow[t]{3}{*}{$M e$} & $(N)$ & 40 & 57 & 25 & 20 & 15 & 33 & 30 & 10 & 27 & 13 & 34 \\
\hline & 154 & 0.000 & 0.000 & 0.000 & 0.000 & 0.000 & 0.000 & 0.000 & 1.000 & 0.000 & 0.000 & 0.000 \\
\hline & 100 & 1.000 & 1.000 & 1.000 & 1.000 & 1.000 & 1.000 & 1.000 & 0.000 & 1.000 & 1.000 & 1.000 \\
\hline \multirow[t]{6}{*}{$M d h$} & $(N)$ & 36 & 50 & 23 & 12 & 10 & 23 & 14 & 10 & 10 & 12 & 22 \\
\hline & 167 & 0.000 & 0.020 & 0.000 & 0.000 & 0.000 & 0.000 & 0.000 & 0.000 & 0.000 & 0.000 & 0.000 \\
\hline & 126 & 0.000 & 0.000 & 0.022 & 0.000 & 0.000 & 0.000 & 0.000 & 0.000 & 0.000 & 0.000 & 0.000 \\
\hline & 100 & 1.000 & 0.970 & 0.978 & 1.000 & 1.000 & 1.000 & 1.000 & 0.000 & 1.000 & 1.000 & 1.000 \\
\hline & 105 & 0.000 & 0.000 & 0.000 & 0.000 & 0.000 & 0.000 & 0.000 & 1.000 & 0.000 & 0.000 & 0.000 \\
\hline & 46 & 0.000 & 0.010 & 0.000 & 0.000 & 0.000 & 0.000 & 0.000 & 0.000 & 0.000 & 0.000 & 0.000 \\
\hline \multirow[t]{6}{*}{$I d h$} & $(N)$ & 40 & 60 & 25 & 20 & 15 & 35 & 30 & 30 & 27 & 14 & 35 \\
\hline & 131 & 0.000 & 0.000 & 0.000 & 0.000 & 0.000 & 0.014 & 0.000 & 0.000 & 0.019 & 0.000 & 0.000 \\
\hline & 100 & 0.975 & 0.967 & 0.960 & 0.975 & 1.000 & 0.986 & 1.000 & 0.000 & 0.981 & 1.000 & 1.000 \\
\hline & 85 & 0.025 & 0.017 & 0.040 & 0.025 & 0.000 & 0.000 & 0.000 & 0.000 & 0.000 & 0.000 & 0.000 \\
\hline & 55 & 0.000 & 0.000 & 0.000 & 0.000 & 0.000 & 0.000 & 0.000 & 1.000 & 0.000 & 0.000 & 0.000 \\
\hline & 44 & 0.000 & 0.017 & 0.000 & 0.000 & 0.000 & 0.000 & 0.000 & 0.000 & 0.000 & 0.000 & 0.000 \\
\hline \multirow[t]{6}{*}{ Pgm } & $(N)$ & 38 & 54 & 25 & 20 & 14 & 34 & 29 & 29 & 27 & 14 & 35 \\
\hline & 100 & 1.000 & 1.000 & 1.000 & 1.000 & 0.000 & 0.000 & 0.034 & 0.000 & 0.000 & 0.000 & 0.000 \\
\hline & 83 & 0.000 & 0.000 & 0.000 & 0.000 & 0.714 & 0.118 & 0.000 & 1.000 & 0.000 & 1.000 & 0.000 \\
\hline & 66 & 0.000 & 0.000 & 0.000 & 0.000 & 0.071 & 0.118 & 0.103 & 0.000 & 0.000 & 0.000 & 0.229 \\
\hline & 51 & 0.000 & 0.000 & 0.000 & 0.000 & 0.143 & 0.500 & 0.276 & 0.000 & 0.000 & 0.000 & 0.771 \\
\hline & 43 & 0.000 & 0.000 & 0.000 & 0.000 & 0.071 & 0.265 & 0.586 & 0.000 & 1.000 & 0.000 & 0.000 \\
\hline \multirow[t]{3}{*}{ Aat-1 } & $(N)$ & 35 & 48 & 11 & 19 & 8 & 25 & 19 & 26 & 19 & 7 & 23 \\
\hline & -100 & 1.000 & 1.000 & 1.000 & 1.000 & 1.000 & 1.000 & 1.000 & 0.000 & 1.000 & 1.000 & 1.000 \\
\hline & -108 & 0.000 & 0.000 & 0.000 & 0.000 & 0.000 & 0.000 & 0.000 & 1.000 & 0.000 & 0.000 & 0.000 \\
\hline \multirow[t]{4}{*}{ Aat-2 } & $(N)$ & 39 & 59 & 22 & 20 & 14 & 34 & 29 & 30 & 26 & 14 & 35 \\
\hline & 156 & 0.000 & 0.000 & 0.000 & 0.000 & 0.179 & 0.441 & 0.241 & 0.000 & 0.000 & 0.000 & 0.686 \\
\hline & 100 & 0.974 & 0.983 & 1.000 & 1.000 & 0.786 & 0.412 & 0.655 & 0.000 & 0.865 & 1.000 & 0.171 \\
\hline & 44 & 0.026 & 0.017 & 0.000 & 0.000 & 0.036 & 0.147 & 0.103 & 1.000 & 0.135 & 0.000 & 0.143 \\
\hline \multirow[t]{5}{*}{ Fumh-1 } & $(N)$ & 30 & 49 & 21 & 18 & 15 & 33 & 29 & 30 & 25 & 14 & 35 \\
\hline & 333 & 0.000 & 0.000 & 0.048 & 0.000 & 0.000 & 0.030 & 0.000 & 0.000 & 0.000 & 0.000 & 0.029 \\
\hline & -100 & 1.000 & 1.000 & 0.952 & 1.000 & 1.000 & 0.955 & 1.000 & 0.000 & 1.000 & 1.000 & 0.957 \\
\hline & -767 & 0.000 & 0.000 & 0.000 & 0.000 & 0.000 & 0.000 & 0.000 & 1.000 & 0.000 & 0.000 & 0.000 \\
\hline & -1000 & 0.000 & 0.000 & 0.000 & 0.000 & 0.000 & 0.015 & 0.000 & 0.000 & 0.000 & 0.000 & 0.014 \\
\hline \multirow[t]{5}{*}{ Fumh-2 } & $(N)$ & 38 & 57 & 21 & 19 & 15 & 31 & 29 & 30 & 26 & 14 & 32 \\
\hline & 130 & 0.000 & 0.000 & 0.024 & 0.000 & 0.000 & 0.000 & 0.000 & 0.000 & 0.000 & 0.000 & 0.000 \\
\hline & 100 & 0.961 & 0.904 & 0.738 & 0.868 & 0.000 & 0.016 & 0.034 & 0.000 & 0.000 & 0.000 & 0.016 \\
\hline & 42 & 0.039 & 0.096 & 0.238 & 0.132 & 1.000 & 0.984 & 0.966 & 0.000 & 1.000 & 1.000 & 0.984 \\
\hline & 0 & 0.000 & 0.000 & 0.000 & 0.000 & 0.000 & 0.000 & 0.000 & 1.000 & 0.000 & 0.000 & 0.000 \\
\hline \multirow{3}{*}{ G3pdh } & $(N)$ & 40 & 59 & 22 & 20 & 14 & 35 & 27 & 30 & 26 & 14 & 34 \\
\hline & 283 & 0.000 & 0.000 & 0.000 & 0.000 & 0.000 & 0.000 & 0.000 & 1.000 & 0.000 & 0.000 & 0.000 \\
\hline & 100 & 1.000 & 1.000 & 1.000 & 1.000 & 1.000 & 1.000 & 1.000 & 0.000 & 1.000 & 1.000 & 1.000 \\
\hline \multirow[t]{4}{*}{ Tpi } & $(N)$ & 40 & 59 & 25 & 20 & 15 & 35 & 30 & 30 & 27 & 14 & 35 \\
\hline & 151 & 0.000 & 0.000 & 0.000 & 0.000 & 0.000 & 0.000 & 0.000 & 1.000 & 0.000 & 0.000 & 0.000 \\
\hline & 126 & 0.013 & 0.000 & 0.000 & 0.000 & 0.000 & 0.000 & 0.000 & 0.000 & 0.000 & 0.000 & 0.000 \\
\hline & 100 & 0.988 & 1.000 & 1.000 & 1.000 & 1.000 & 1.000 & 1.000 & 0.000 & 1.000 & 1.000 & 1.000 \\
\hline
\end{tabular}

Hosts are abbreviated by giving only the first letter of the generic name, and the three first letters of the species names (eg, B. pen $=$ Betula pendula). See Results and Table 2 for explanation for the three 'Salicaceae' species ('Sal 1-3').

malate dehydrogenase (Mdh, EC 1.1.1.37), isocitrate dehydrogenase (Idh, EC 1.1.1.42), aspartate aminotransferase (Aat-1 and Aat-2, EC 2.6.1.1), triose-phosphate isomerase (Tpi, EC 5.3.1.1), fumarase hydratase (Fumh-1 and Fumh-2, EC 4.2.1.2), and glycerol-3-phosphate dehydrogenase (G3pdh, EC 1.1.1.8).

\section{Data analysis}

Allele frequencies and sample sizes were calculated by using BIOSYS-1 version 1.7 (Swofford and Selander, 1989). Deviations from Hardy-Weinberg equilibrium (HWE) in individual loci were tested by Fisher's exact test in the Genetic Data Analysis program (GDA; Lewis and Zaykin, 2001). Ten thousand permutations were used in the tests, and the obtained significance levels were adjusted using a sequential Bonferroni correction (Rice,
1989). Linkage disequilibrium between pairs of polymorphic loci was tested similarly, but the genotypes in individual loci were preserved in the permutation procedure.

Clustering analyses were performed using the TFPGA version 1.3 program (Miller, 1997). UPGMA clustering analyses were based on Nei's (1978) unbiased genetic distances, and cluster support was inferred by bootstrapping 1000 times over loci. Because the samples collected from S. aucuparia and the Alnus species had no alleles in common (Table 1), genetic distances between these two groups could not be calculated. Consequently, two separate clustering analyses were performed: when the S. aucuparia sample was included, the Alnus samples were excluded, and vice versa. 


\section{Results}

Allele frequencies and sample sizes in individual loci are presented in Table 1. Seven statistically significant deviations from HWE were found in the samples. With the exception of the $I d h$ locus in the B. pubescens sample, all deviations occur in the Pgm and Aat-2 loci in all Populus and Salix samples (all Bonferroni corrected P:s $<0.05$ ), caused by a deficiency of heterozygotes. In addition, these two loci are in statistically significant linkage disequilibria in all samples collected from these three host species (all uncorrected $P<0.02$ ). In the other samples, no statistically significant linkage disequilibria were found.

Based on these observations, the individuals collected from $P$. tremula, S. phylicifolia and S. caprea were sorted according to their genotype at the Pgm locus, at which heterozygotes between some alleles were totally missing (only $\mathrm{Pgm}^{51 / 66}$ heterozygotes were found); the resulting 'sorted' samples are shown in Table 1 as three putative species ('Salicaceae 1-3'), and their corresponding genotypes and hosts are shown in Table 2 . Because of the linkage disequilibrium between the Pgm and Aat-2 loci, the sorting also leads to clear differences in allele frequencies at the Aat-2 locus (Tables 1 and 2). Three individuals having missing data in the Pgm locus were excluded from the sorted data set, as was one individual having a typical Betula/Alnus genotype. This last individual may represent an oviposition error (see Discussion). In the sorted data set, most deviations from HWE are no longer statistically significant in the 'Salicaceae 1-3' samples, but there is still a statistically significant deviation in 'Salicaceae $3^{\prime}$ at the Aat-2 locus $(P<0.001)$. This may be caused by the fact that weakly stained Aat- $2^{44 / 156}$ heterozygotes may have been inadvertently scored as Aat-2 ${ }^{100 / 100}$ homozygotes, because the heterodimer is stained more strongly than the homodimers. However, excluding these individuals from the sorted data set has no meaningful effect on the results and conclusions in this study. The only statistically significant linkage disequilibrium in the sorted data set is between Fumh-1 and Fumh-2 in 'Salicaceae 3 ', but the disequilibrium is not significant if a Bonferroni correction is made (uncorrected $P=0.027$ ).

The UPGMA clustering analysis using the original data

Table 2 The three putative Salicaceae-feeding species that were obtained by sorting the individuals collected from Populus tremula, Salix phylicifolia, and S. caprea according to their genotype at the Pgm locus (see Results), and the host plants on which these individuals were found. Because of the linkage disequilibrium between $P g m$ and Aat-2, the sorting also results in clear differences in allele frequencies at the Aat-2 locus (see Table 1)

\begin{tabular}{lccl}
\multirow{2}{*}{$\begin{array}{l}\text { Putative } \\
\text { species }\end{array}$} & \multicolumn{2}{c}{ Allele(s) found in locus } & Hosts \\
\cline { 2 - 3 } & Pgm & Aat-2 & \\
\hline Salicaceae 1 & 43 & $100 / 44$ & $\begin{array}{l}\text { P. tremula (1), S. phylicifolia } \\
\text { (9), S. caprea (17) }\end{array}$ \\
Salicaceae 2 & 83 & 100 & $\begin{array}{l}\text { P. tremula (10), S. phylicifolia } \\
\text { (4) }\end{array}$ \\
Salicaceae 3 & $51 / 66$ & $44 / 100 / 156$ & $\begin{array}{l}\text { P. tremula (3), S. phylicifolia } \\
\text { (21), S. caprea (11) }\end{array}$
\end{tabular}

(21), S. caprea (11)

Numbers in parentheses after each host species refer to the number of larvae collected from that host. set (Figure 1a) shows that the samples collected from the two Betula species and the two Alnus species form a distinct and well supported cluster. The samples collected from Populus tremula and the two Salix species are grouped together in a more heterogeneous cluster. The sample collected from $S$. aucuparia is extremely different from the other samples. When the clustering analyses are redone using the sorted data set, the results are otherwise similar to the original data, except that the heterogeneity within the Salicaceae-feeding cluster is increased (Figure 1b).

Thus, the results indicate that there are five Phytobia species that feed on the eight host species included in this study: the Phytobia larvae collected from the Betula and Alnus species represent a single species, as do the larvae from S. aucuparia. However, the larvae from Populus tremula and the two Salix species apparently represent three species with partially overlapping feeding ranges. The distribution of individuals on different host species is statistically significantly different between the Salicaceaefeeding species $\left(\chi_{4}^{2}=40.23, P<0.001\right.$; see Table 2$)$. The assumptions of the $\chi^{2}$-test are violated because some individuals were collected from the same tree, and thus they may be siblings (however, larvae representing different species could be found on single tree individuals). Thus, the test was repeated so that if multiple larvae representing a given species had been collected from a given tree individual, they were treated as only one larva, ie, it

a

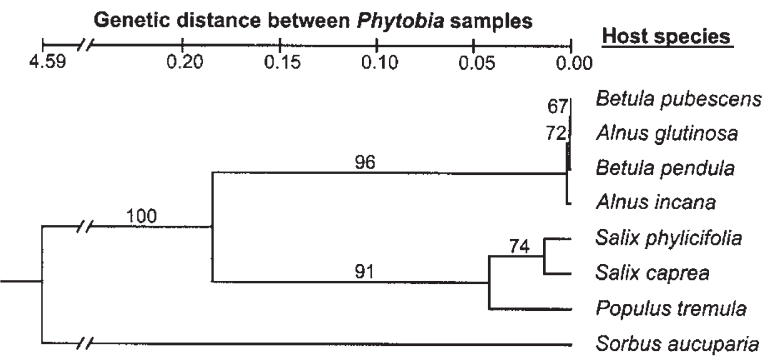

b

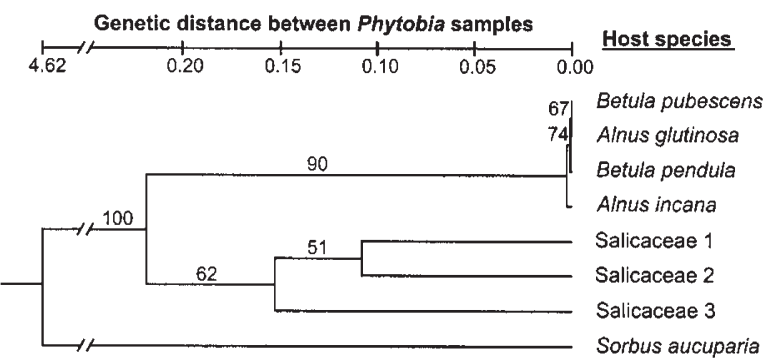

Figure 1 UPGMA clustering dendrograms of Phytobia samples collected from eight different host tree species, based on pairwise Nei's (1978) unbiased genetic distances calculated from 10 polymorphic allozyme loci. Host species are shown to the right of the dendrograms, numbers above branches are bootstrap proportions (\%) from 1,000 replicates. Results are shown (a) for the original data set, and (b) for a data set in which the Salicaceae-feeding individuals have been sorted into three putative species (Salicaceae 1-3) according to their genotype at the Pom locus (see Results and Table 2 for explanation, and list of hosts for these species). In both cases, analyses including the $S$. aucuparia sample were made while excluding the Alnus samples, and vice versa (see Materials and methods). Note the cut in the scale. 
was assumed that they represent the offspring of a single female. The result of the analysis remains essentially the same $\left(\chi_{4}^{2}=25.76, P<0.001\right)$.

The aforementioned results are supported by the results obtained in a pilot study, conducted in 1997 using larvae collected from five of the host species in 1996 ( $n$ =9-41 larvae per host species; results not shown). In the pilot survey, allele frequencies were close to the ones observed in this study and, consequently, the larvae collected from the two Betula species and A. incana were very different from the samples collected from the two Salix species. Likewise, all 'Salicaceae 1-3' species were observed in the Salix samples in the preliminary study.

\section{Discussion}

Although Phytobia has been extensively studied in Europe, the number of species that actually exist in the region is still unclear. As stated above, Kangas (1935, 1949) considered that there are five Phytobia species that feed on the tree species represented in this study: $P$. betulae on Betula spp., P. aucupariae on S. aucuparia, and three species ( $P$. cambii, P. barnesi, and P. tremulae) on hosts belonging to the Salicaceae. Later, Spencer (1976) considered that the presence/absence of the mid-tibial bristle, which Hendel (in Barnes, 1933) and Kangas (1949) had mainly used to separate the Salicaceae-feeding species from each other, was not a clear enough character for species separation. Consequently, Spencer (1976, see also Spencer, 1990) considered that there exists only one European Salicaceae-feeding species (ie, P. cambii), and this view has later been followed by others (Martinez et al, 1985; von Tschirnhaus, 2000). In the end, von Tschirnhaus (2000) even synonymized $P$. betulae with $P$. cambii, which would mean that there would be only two European Phytobia species on the hosts in this study: P. cambii on Betulaceae and Salicaceae hosts, and P. aucupariae on S. aucuparia.

The results from our study clearly support Kangas' $(1935,1949)$ interpretation of the species situation in Phytobia. The five species that can be distinguished in our study are characterized by fixed differences in various loci. The clearest one is the $S$. aucuparia species $(=P$. aucupariae), and the apparently single species on Betula and Alnus $\left(=P\right.$. betulae) is distinguished by the $P g m^{100}$ allele (Table 1). One individual having this allele was found on $S$. caprea, but because the individual was homozygous for the allele, it seems more likely that it represents an oviposition error rather than evidence for hybridization between species. Oviposition errors are probably a common phenomenon in phytophagous insects, although quantitative studies are rare (Larsson and Ekbom, 1995). The three Salicaceae species can be separated on the basis of their genotype at the Pgm locus (Table 2). We note that these Salicaceae-feeding types were also found in the preliminary survey that was conducted with samples collected from the study area in the previous summer (see Results). The three species apparently represent $P$. cambii, $P$. barnesi, and $P$. tremulae, but further study is needed in order to establish which 'allozyme species' corresponds to which morphospecies.

Studies on insect host races have shown that hostdependent disruptive selection can cause and maintain large differences in allele frequencies at allozyme loci, even when there is considerable gene flow between the host races (Feder et al, 1997; Filchak et al, 2000; Drès and Mallet, 2002). In the case of Phytobia, host-associated disruptive selection seems an unlikely explanation for the results above, because there are fixed differences at single or multiple loci and, more importantly, the 'Salicaceae 13 ' species overlap in their host use. Thus, our results indicate that all five species that can be identified on the basis of allozyme data are true biological species (sensu Mayr, 1963) that do not interbreed.

At the species level, the host associations can clearly be explained by the taxonomic affinities of the hosts. Betula and Alnus, which support a single Phytobia species (=P. betulae), belong to the plant family Betulaceae. In Central Europe, P. betulae has been reported to feed on Corylus and Carpinus, which also belong to the same family (Spencer, 1990). Sorbus aucuparia, which supports a very distinct Phytobia species (= P. aucupariae), belongs to the family Rosaceae, and the three species ('Salicaceae 1$3^{\prime}$ ) with overlapping host associations all feed on trees belonging to the Salicaceae. Thus, the results conform to the common pattern that when an herbivorous insect is oligo- or polyphagous, the hosts tend to be closely related (Bernays and Graham, 1988).

However, on a larger scale it is evident that the evolution of host use in Phytobia cannot be explained by simple parallel cladogenesis (= cospeciation) between the flies and their host plants. Although UPGMA clustering is sensitive to rate heterogeneity in the lineages that are being studied (Swofford et al, 1996), the species occurring on $S$. aucuparia is so different from the four others that it is highly likely that it was the first one to diverge. In fact, the genetic distance between this species and the other samples is more typical of insects in separate genera (see Emelianov et al, 1995). This is also supported by the fact that $P$. aucupariae has a rather distinct morphology and life cycle: whereas the larvae of species that feed on Betulaceae and Salicaceae exit the trees in the autumn to pupate and overwinter on the ground, the larvae of $P$. aucupariae overwinter in the trees and pupate on the ground in the next spring (Kangas, 1949; Spencer, 1976). Species having a rather similar morphology and life cycle are also known from other tree species belonging to Rosaceae (Grossenbacher, 1915; Kangas, 1955; Spencer and Steyskal, 1986). However, the Rosaceae has probably been colonized independently at least twice, because some of the Rosaceae-feeding species overwinter as pupae on the ground (Spencer, 1976, 1990; Spencer and Steyskal, 1986). In any case, the branching pattern observed in our study, ie, (Rosaceae(Betulaceae, Salicaceae)), clearly contradicts the current hypothesis of the phylogenetic relationships between the host species represented in this study, ie, (Salicaceae(Betulaceae, Rosaceae)) (Angiosperm Phylogeny Group, 1998). A somewhat similar result was found by Scheffer and Wiegmann (2000) in the case of agromyzid Phytomyza leaf miners that mine in the leaves of hollies (Ilex spp.), because they also could rule out an explanation based on cospeciation. Together, these results from two distantly related agromyzid taxa provide further support for the view that strict parallel cladogenesis between insects and plants is a rare phenomenon (Mitter et al, 1991).

It has been suggested that mining larval habits may predispose insects to cospeciation with their hosts, but clearly the situation in Phytobia is very different from the situation in the Phyllobrotica and Tetraopes beetles dis- 
cussed by Farrell and Mitter $(1990,1998)$. In contrast to the tissues of the hosts of these beetles (the Lamiales and Asclepiadaceae, respectively), the differentiating xylem in deciduous trees is probably not strongly defended by secondary compounds and, thus, host chemistry may present only weak barriers for colonization by Phytobia. This implies that larval endophagy per se does not affect the likelihood of parallel cladogenesis, but may do so in combination with heavy chemical defence of the hosts (see also Farrell and Mitter, 1990, 1998).

In conclusion, it is evident that in Finland the genus Phytobia is represented by at least five reproductively isolated species, and this is probably also true elsewhere in Europe. Allozyme electrophoresis appears to be a powerful tool for species identification in this genus. More thorough sampling of different tree species is needed, because it is likely that new Phytobia species can be found on unstudied, economically unimportant tree species. The host use of the individual species in this study seems to be explained by the taxonomic affinities of the host plants, but on a larger scale the evolution of host-plant associations cannot be explained by strict cospeciation between Phytobia and their hosts. A phylogenetic study of the whole Phytobia would add to the knowledge of evolution in the Agromyzidae, as well as in phytophagous insects in general.

\section{Acknowledgements}

We thank the Punkaharju Research Area of the Finnish Forest Research Institute for kindly providing sampling sites. We are especially grateful to Anne Matilainen, Henriikka Hyvönen, Tomi Nuora, and Jari Salminen for assistance in the collection of larvae, and to Jorma Tahvanainen, Pauline Roberts, and two anonymous reviewers for their comments on the manuscript. Funding for this study was provided by the Ministry of Agriculture and Forestry of Finland, the Emil Aaltonen Foundation, and the Academy of Finland.

\section{References}

Aguin-Pombo D (2002). Genetic differentiation among hostassociated Alebra leafhoppers (Hemiptera: Cicadellidae). Heredity 88: 415-422.

Angiosperm Phylogeny Group (1998). An ordinal classification for the families of flowering plants. Ann MO Bot Gard 85: 531-553.

Barnes HF (1933). A cambium miner of basket willows (Agromyzidae) and its inquiline gall midge (Cecidomyidae). Ann Appl Biol 20: 498-519.

Bernays E, Graham M (1988). On the evolution of host specificity in phytophagous arthropods. Ecology 69: 886-892.

Condon MA, Steck GJ (1997). Evolution of host use in fruit flies of the genus Blepharoneura (Diptera: Tephritidae): cryptic species on sexually dimorphic host plants. Biol J Linn Soc 60: 443-466.

De Barro PJ, Sherratt TN, Brookes CP, David O, Maclean N (1995). Spatial and temporal genetic variation in British field populations of the grain aphid Sitobion avenae (F.) (Hemiptera: Aphididae) studied using RAPD-PCR. Proc R Soc Lond B 262: 321-327.

Diehl SR, Bush GL (1984). An evolutionary and applied perspective of insect biotypes. Annu Rev Entomol 29: 471-504.

Drès $M$, Mallet J (2002). Host races in plant-feeding insects and their importance in sympatric speciation. Phil Trans $R$ Soc Lond B 357: 471-492.

Emelianov I, Mallet J, Baltensweiler W (1995). Genetic differentiation in Zeiraphera diniana (Lepidoptera: Tortricidae, the larch budmoth): polymorphism, host races or sibling species? Heredity 75: 416-424.

Farrell B, Mitter C (1990). Phylogenesis of insect/plant interactions: have the Phyllobrotica leaf beetles (Chrysomelidae) and the Lamiales diversified in parallel? Evolution 44: 1389-1403.

Farrell BD, Mitter C (1998). The timing of insect/plant diversification: might Tetraopes (Coleoptera: Cerambycidae) and Asclepias (Asclepiadaceae) have co-evolved? Biol J Linn Soc 63: 553-577.

Feder JL, Chilcote CA, Bush GL (1988). Genetic differentiation between sympatric host races of the apple maggot fly Rhagoletis pomonella. Nature 336: 61-64.

Feder JL, Roethele JB, Wlazlo B, Berlocher SH (1997). Selective maintenance of allozyme differences among sympatric host races of the apple maggot fly. Proc Natl Acad Sci USA 94: 11417-11421.

Ferguson A (1980). Biochemical Systematics and Evolution. Blackie: Glasgow.

Filchak KE, Roethele JB, Feder, JL (2000). Natural selection and sympatric divergence in the apple maggot Rhagoletis pomonella. Nature 407: 739-742.

Greene CT (1914). The cambium miner in river birch. J Agric Res 1: 471-474 (+ illustrations).

Gregory R, Wallner W (1979). Histological relationship of Phytobia setosa to Acer saccharum. Can J Bot 57: 403-407.

Grossenbacher JG (1915). Medullary spots and their cause. Bull Torrey Bot Club 42: 227-239 (+ illustrations).

Hanson JB, Benjamin DM (1967). Biology of Phytobia setosa, a cambium miner of sugar maple. J Econ Entomol 60: 1351-1355.

Jermy T (1984). Evolution of insect/host plant relationships. Am Nat 124: 609-630.

Kangas E (1935). Die Braunfleckigkeit des Birkenholzes und ihr Uhrheber Dendromyza (Dizygomyza) betulae n. sp. Vorläufige Mitteilung. Comm Inst For Fenn 22: 1-31.

Kangas E (1949). Die Dendromyza-Arten von Eberesche, Espe und Salweide und ihre Biologie. Ann Ent Soc Fenn 14 (Suppl): 106-117.

Kangas E (1955). Dendromyza cerasiferae n.sp. (Dipt., Agromyzidae) from England. Ann Ent Soc Fenn 21: 165-170.

Larsson S, Ekbom B (1995). Oviposition mistakes in herbivorous insects: confusion or a step towards a new host plant? Oikos 72: 155-160.

Lewis PO, Zaykin D (2001). Genetic Data Analysis (GDA): Computer program for the analysis of allelic data. Version 1.0 (d16c). Free program distributed by the authors over the internet from http://lewis.eeb.uconn.edu/lewishome/software.html.

Martinez M, Gumez JL, Munnier P (1985). Un ravageur mal connu: la mouche mineuse du cambium des peupliers. Phytoma 374: 51-53.

Mayr E (1963). Animal Species and Evolution. Harvard University Press: Cambridge.

McPheron BA, Smith DC, Berlocher SH (1988). Genetic differences between host races of Rhagoletis pomonella. Nature 336: 64-66.

Miller MP (1997). Tools for Population Genetics Analyses (TFPGA) 1.3: A Windows program for the analysis of allozyme and molecular population genetic data. Computer software distributed by author.

Mitter C, Farrell B, Futuyma DJ (1991). Phylogenetic studies of insect-plant interactions: insights into the genesis of diversity. Trends Ecol Evol 6: 290-293.

Nei M (1978). Estimation of average heterozygosity and genetic distance from a small number of individuals. Genetics 89: 583-590.

Nowakowski JT (1962). Introduction to a systematic revision of the family Agromyzidae (Diptera) with some remarks on host plant selection by these flies. Ann Zool Warsz 20: 67-183.

Nyman T (2002). The willow bud galler Euura mucronata Hartig 
(Hymenoptera: Tenthredinidae): one polyphage or many monophages? Heredity 88: 288-295.

Nyman T, Roininen H, Vuorinen JA (1998). Evolution of different gall types in willow-feeding sawflies (Hymenoptera: Tenthredinidae). Evolution 52: 465-474.

Pornkulwat S, Skoda SR, Thomas GD, Foster JE (1998). Random amplified polymorphic DNA used to identify genetic variation in ecotypes of the European corn borer (Lepidoptera: Pyralidae). Ann Entomol Soc Am 91: 719-725.

Rice, WR (1989). Analyzing tables of statistical tests. Evolution 43: $223-225$

Roininen H, Vuorinen J, Tahvanainen J, Julkunen-Tiitto R (1993). Host preference and allozyme differentiation in shoot galling sawfly, Euura atra. Evolution 47: 300-308.

Scheffer S (2000). Molecular evidence of cryptic species within the Liriomyza huidobrensis (Diptera: Agromyzidae). J Econ Entomol 93: 1146-1151.

Scheffer S, Wiegmann BM (2000). Molecular phylogenetics of the holly leafminers (Diptera: Agromyzidae: Phytomyza): species limits, speciation, and dietary specialization. Mol Phylogenet Evol 17: 244-255.

Spencer KA (1976). The Agromyzidae (Diptera) of Fennoscandia and Denmark. Fauna Ent Scand 5: 1-606.

Spencer KA (1990). Host Specialization in the World Agromyzidae (Diptera). Kluwer Academic Publishers: London.

Spencer KA, Steyskal GC (1986). Manual of the Agromyzidae (Diptera) of the United States. United States Department of Agriculture: Washington.
Süss H, Müller-Stoll WR (1980). Das fossile Holz Pruninium gummosum Platen emend. Süss u. Müller-Stoll aus dem Yellowstone Nationalpark und sein Parasit Palaeophytobia prunorum sp. nov. nebst Bemerkungen über Markflecke. In: Vent W (ed) 100 Jahre Arboretum Berlin, Humboldt University: Berlin. pp 343-364.

Swofford DL, Selander RB (1989). BIOSYS-1. A computer program for the analysis of allelic variation in population genetics and biochemical systematics. Release 1.7. University of Illinois: Urbana.

Swofford DL, Olsen GJ, Waddell PJ, Hillis DM (1996). Phylogenetic inference. In: Hillis DM, Moritz C, Mable BK (eds) Molecular Systematics, 2nd edn. Sinauer: Sunderland. pp 407-514.

von Tschirnhaus M (1971). Unbekannte Stridulationsorgane bei Dipteren und ihre Bedeutung für Taxonomie und Phylogenetik der Agromyziden. Beitr Ent 21: 551-579.

von Tschirnhaus M (2000). Agromyzidae. Nova Suppl Ent 14: 133-149.

Vuorinen J (1984). Electrophoretic expression of genetic variation and duplicate gene activity in vendace, Coregonus albula (Salmonidae). Hereditas 101: 85-96.

Ylioja T (2000) Relationship between Phytobia betulae and its host tree Betula sp.. Faculty of Forestry, University of Joensuu, Research Notes 112: 1-26.

Ylioja T, Saranpää P, Roininen H, Rousi M (1998). Larval tunnels of Phytobia betulae (Diptera: Agromyzidae) in birch wood. J Econ Entomol 91: 175-181. 